\title{
TRANSTONO MENTAL: VIDAS EM TRANSFORMAÇÃO
}

Autora: Cristiane do Nascimento ${ }^{1}$

\section{RESUMO}

Esta pesquisa foi realizada em face da importância de do desenvolvimento da cooperativa enquanto conquista autonomia para os pacientes do CAPS II do município de Araucária, e quebrar paradigmas na sociedade, quanto a capacidade de Pessoas om transtorno mental. A produção de estopa enquanto construção de caráter de cidadania para pacientes e seus familiares, e sua função social na sustentabilidade com aproveitamento de resíduos que são descartados em empresas têxteis, com proteção ao meio ambiente. A metodologia utilizada foi Pesquisa Bibliográfica, a qual nos auxiliou a construção de todo o referencial teórico deste trabalho. Quanto ao tipo de Pesquisa teremos como base à de natureza qualitativa, desta maneira, a observação participante será um dos instrumentos de pesquisa utilizado para coleta de dados subjetivos. Durante esse processo se fez necessário a adaptação no planejamento da construção do sonho, de cooperativa para a implantação do Projeto Arausol. A proposta de estudo para identificar essa viabilidade da autonomia dos pacientes, foi comprovada com o decorrer da pesquisa, com o fortalecimento da autonomia, a construção de sujeitos de direitos e a inserção produtiva. Também foi nítido a questão da autoestima dos pacientes, como cidadãos produtivos e protetores do meio ambiente, sujeitos de direitos.

Palavras-chave: Cidadania; Inserção Produtiva; Sustentabilidade; Autonomia, Geração de Renda, Arausol, Cooperativa, Economia Solidária, Nova Ordem Societária.

\begin{abstract}
This research was carried out in view of the importance of developing the cooperative while gaining autonomy for CAPS II patients in Araucária city, and breaking paradigms in society regarding the capacity from people with mental disorders. The production of oakum related to a citizenship formation on patients and their families, its social function on sustainability using waste witch are discarded in textile companies, and protecting the environment. The methodology used was Bibliographic Research, which helped us to build the entire theoretical framework. As for the type of research, it was based on the qualitative nature, in this way, participant observation was one of the research instruments used to collect subjective data. During this process it was necessary to adapt the planning for the construction of the dream, from a cooperative to the implementation of the Arausol Project. The proposal to identify this viability of autonomy's patients was proven during the course of the research, with the strengthening of autonomy, the construction of entitled subjects and productive insertion. The issue of patients self-esteem, as productive citizens and protectors of the environment, entitled subjects, was also clear.
\end{abstract}

Keywords: Citizenship; Productive Insertion; Sustainability; Autonomy, Income Generation, Arausol, Cooperative, Solidarity Economy, New Corporate Order.

\section{INTRODUÇÃO}

O objetivo deste artigo foi analisar a possibilidade de implantação de uma cooperativa, com os usuários do CAPS II de Araucária. A motivação desta pesquisa foi responder a seguinte problemática: Qual a possibilidade da implantação de uma cooperativa dos pacientes do CAPS II de Araucária para produção de estopa e sua contribuição à sustentabilidade ambiental?

Buscou-se entender qual a real possibilidade de os usuários com transtorno mental estar em conjunto neste processo cooperativo, com autonomia, inserção na sociedade e principalmente contribuir com a sustentabilidade do meio ambiente. Com produção de estopa, utilizando rejeitos de tecidos, de empresas de confecção, descartados.

1 Especialista em Gestão Pública pela Faculdade FAEL, Especialista em Metodologia para o Enfrentamento a Violência contra crianças e adolescentes pela Pontifícia Universidade Católica (PUCPR), Curitiba, PR. Assistente Social formada pelas Faculdades Integradas Espirita, trabalhou no CREAS do município de Piraquara, no momento trabalha no município de Araucária, no CAPS II. cristiane.rcg@gmail.com 
Justifica-se esse estudo pois a produção de estopa buscou esse caráter de cidadania para usuários do CAPS II e seus familiares, também tem sua função social na sustentabilidade com aproveitamento de resíduos que são descartados em empresas têxteis, com proteção ao meio ambiente.

Através deste trabalho compartilhar a experiência do trabalho no CAPS II, no Município de Araucária no Paraná. Acreditamos que o ser humano se constrói na vivência e no contato com o outro, logo somos a soma de saberes, que apreendemos no decorrer da caminhada.

Esse foi nosso foco principal, dividir e partilhar, com profissionais, familiares, usuários e a sociedade em geral. Partilhando, compreendendo a história, as lutas, as conquistas, poderemos conscientemente fazer parte da mudança para um mundo melhor, mais justo, mais digno, sem exclusão, sem violência, com a inclusão dos nossos usuários.

Para compreender esse processo no CAPS II, foi necessário iniciar com uma retrospectiva na Saúde Mental e a Reforma da Psiquiatria.

Buscou-se publicizar a história construída no CAPS II, com a participação efetiva de usuários da Saúde Mental, familiares, profissionais e simpatizantes da causa. Descrever como as pessoas sensibilizadas, com a compreensão do porquê do Projeto Arausol, apoiaram de forma amorosa e efetiva essa construção. A experiência da Arausol, grupo de Geração de Renda, pautada na Economia Solidária.

Neste processo teve conquistas, avanços, desafios, angustias e principalmente aprendizado. Como nos constituímos, quem nos auxiliou neste movimento, e como ainda temos muito a caminhar.

\section{OS EXILADOS SOCIALMENTE OU OS EXILADOS DO MUNDO}

\footnotetext{
"O passado não se pode ser considerado como exemplo, é lição para se meditar, não para se reproduzir. " Mário de Andrade

Semana de Arte Moderna - 1922
}

Historicamente pessoas com transtorno mental, foram excluídas e sem perspectiva de inclusão social, nos anos 70 foi uma época de embates contra o regime militar e, na saúde mental, as denúncias a maus tratos. Em meados dos anos 80 a da saúde é marcada por movimentos de mudanças, envolvendo novos paradigmas e práticas assistenciais, que viriam a legitimar o Sistema Único de Saúde na Constituição de 1988. A Saúde é reconhecida como direito de todos e dever do Estado. Vinculado diretamente com as questões políticas da época, emerge no país o Movimento dos Trabalhadores em Saúde Mental, impulsionando a criação do movimento de Reforma Psiquiátrica.

Os pacientes com transtorno anteriormente a Reforma da Psiquiatria, eram institucionalizados em hospitais, e não tinha acesso em muitas vezes um tratamento digno, a inclusão familiar e social, acesso ao trabalho, cultura e lazer. Situações gravíssimas de abandono, tortura, negligencia grave, entre outras situações foram denunciadas nessa época.

A população que sofre de algum transtorno mental é reconhecida como uma das mais excluídas socialmente, diante dessa cultura de exclusão e esconder a Pessoa em sofrimento mental ocorreram atrocidades em nosso país. Historicamente essas pessoas foram segregadas as instituições asilares, não para tratamento mas para o abandono nesses locais. Também eram colocados em porões 
em casas, não saiam com os membros da família, pois eram considerados uma "aberração", ou em outros casos eram infantilizados, incapacitados, para minimante uma vida mais autônoma. Essas Pessoas com Transtorno Mental eram isolados, não tinham direitos a convivência familiar e comunitária, eram excluídas, como se apagadas da história.

A proposta de uma rede substitutiva ao hospital psiquiátrico cria os novos serviços que orientam a redução progressiva dos leitos em Hospital Psiquiátrico, logo após a reforma o tratamento em saúde mental deve ser realizado em CAPS, buscando a inserção na sociedade, segundo a Lei 10.216/01, que dispõe sobre os direitos das Pessoas com Transtornos Mentais e redireciona o modelo assistencial : "ser tratado preferencialmente em serviços comunitários de saúde mental (...); A internação, em qualquer de suas modalidades só será indicada quando os recursos extra-hospitalares se mostrarem insuficientes"; (...) O tratamento visará, como finalidade permanente, a reinserção social do paciente em seu meio “

Fortalecendo essa Rede, esclarecendo e incluindo esses sujeitos no Território.

\section{CAPS OQUE SÃO? E PARA QUE VIERAM?}

O que melhora o atendimento é o contato afetivo de uma pessoa com a outra.

O que cura é a alegria, o que cura é a falta de preconceito. Nise da Silveira

É função dos CAPS prestar atendimento clínico em regime de atenção diária, buscando evitar as internações em hospitais psiquiátricos promovendo a inserção social das pessoas com transtornos mentais através de ações intersetoriais

Além dessa barreira física historicamente colocada referida inicialmente, hoje tem-se uma sequela desta história, pois muitas vezes os usuários são segregados de forma velada nos atendimentos na comunidade e até em alguns locais na Rede Sócio assistencial. Referindo que não sabem como lidar com o "paciente" o "louco", e então nem mesmo se tenta a convivência e ou/atendimento, apenas se exclui ou é encaminhado apenas ao "CAPS" que sabe cuidar "deles".

Não percebemos que a sociedade ainda imprime esta forma de preconceito e também alguns profissionais que não compreendem a importância da inclusão, da luta para que fosse conquistado espaço para essas pessoas, estarem convivendo e garantindo seus direitos.

Essas barreiras devem ser rompidas com o fortalecimento dos territórios, com os CAPS fortemente estando presentes nas comunidades, nos serviços socioassistencias, seja saúde, assistência social, educação, cultura, trabalho e emprego entre outros. Colocando deve-se trabalhar em Rede e não novamente "asilar" os usuários nos CAPS, como já foram asilados nos manicômios.

Conhecendo o contexto histórico que seja possível quebrar preconceitos, questionar os locais, os profissionais, a sociedade, sobre os movimentos de repetição da exclusão perpetrada através da história?

Seja com falas preconceituosas e/ou pejorativas, seja com o movimento de "empurrar " para o outro que vai saber como "tratar" deles, seja quando não se fortalece a família, reforçando o seu papel protetor e de cuidado. Questionar-se enquanto profissionais que não sejam os agentes de reprodução do 
asilamentos. Quando as famílias procuram a Rede de Atenção, com dificuldades de convívio, que seja a única saída a institucionalização deste usuário. Refletir os movimentos de sociedade é fundamental para que se possa mudar o rumo do futuro, com participação de todos, principalmente dos usuários, os maiores beneficiados neste processo.

\section{A CAMINHADA NO CAPS II DE ARAUCÁRIA}

O conhecimento é social e histórico. Ele não se dá fora do tempo nem fora do espaço: há uma historicidade na ciência, há uma historicidade no conhecimento, que tem limites.

O sujeito que conhece está histórica e socialmente limitado no ato de conhecer. E estes limites são sociais e não apenas individuais.

Paulo Freire

O CAPS II de Araucária local deste trabalho, é um órgão público, na Secretaria de Saúde do município, que atende pacientes com transtorno mental, e características descritas no Artigo $3^{\circ}$ da Portaria 336/2002, são atendidos prioritariamente os pacientes com transtornos mentais severos e persistentes em sua área territorial, semi-intensivo e não intensivo. Diante das atribuições da equipe atendimento em grupos com psicoterapia, grupo operativo, atividades de suporte social, entre outras; atendimento em oficinas terapêuticas; atividades comunitárias enfocando a integração do paciente na comunidade e sua inserção familiar e social. Neste contexto o CAPS II, com sua equipe técnica auxilia na organização e sede o espaço púbico para a Associação Dr. Régis Viola.

No tratamento no CAPS II, tem uma particularidade própria que chama a atenção, que se trata da participação dos usuários realmente com efetividade. Sabe-se que em muitas instituições públicas tem na letra da Política Pública, a obrigatoriedade da participação do usuário.

Mas ver a efetividade dessa teoria, é transformador. Com assembleias semanais, decisões sobre a alimentação, manutenção do espaço, com votações, usuários com direito a voz e voto, decisões tomadas por pessoas que na maioria da sociedade os veem como incapazes. Usuários fortalecidos e ocupando espaços fora do CAPS II, como no Conselho Municipal de Saúde de Araucária (COMUSAR).

Participando nas reuniões no COMUSAR, quando se sentem fragilizados em dúvidas sobre as temáticas abordadas, buscam os profissionais, e juntos, buscam entender as demandas, para que decidam o que realmente é melhor para a comunidade. Assim atuam com segurança no Conselho Municipal de Saúde, por efetivação de seus direitos.

Sempre é refletido com os usuários a caminhada na psiquiatria, e a importância do Cuidado em Liberdade. Muitos tiverem anos de isolamento e conhecem essa história por terem vivenciado esse processo. Reflete-se com os mesmos da importância da participação popular, deles e de suas famílias.

O CAPS II é um espaço acolhedor, participativo, onde os usuários refletem sobre o cotidiano do serviço e o que pode ser melhorado, e qual o seu papel neste local? Esse local é um espaço para esse indivíduo que é visto como "louco", para que se expresse, seja acolhido, desenvolva suas habilidades e potencialidades, acompanhamento da Rede de apoio (família, amigos, colegas de trabalho, companheiro de escola e pessoas da comunidade, outros), e fortalecendo a Rede Socioassistencial.

Os CAPS são instituições destinadas a acolher os pacientes com transtornos mentais, estimular sua integração social e familiar, apoiá-los em suas iniciativas de busca da 
autonomia, oferecer-lhes atendimento médico e psicológico. Sua característica principal é buscar integrá-los a um ambiente social e cultural concreto, designado como seu "território", o espaço da cidade onde se desenvolve a vida quotidiana de usuários e familiares. Os CAPS constituem a principal estratégia do processo de reforma psiquiátrica. (BRASIL, 2004).

Neste fortalecimento da Rede de apoio, para que essas pessoas sejam amparadas em aspectos físicos e também afetivos. Essa Rede de apoio traz um conforto de pertencimento a um grupo, a segurança na questão de aspectos físicos muito importantes nessa vida, e afetivos, sentir-se amado, respeitado, admirado, e assim melhora a auto estima desses usuários.

A Associação dos pacientes, muito fortalecida e atuante no município. É composta por pacientes do CAPS II, seus familiares e simpatizantes da causa de Saúde Mental. Há muitos anos os pacientes buscam implantar uma Cooperativa Social, com cunho terapêutico e de geração de renda, mas sem sucesso. Discutem em assembleias na associação, com a participação dos associados.

Entender e verificar o desenvolvimento da cooperativa enquanto conquista autonomia para os usuários e quebrar paradigmas na sociedade, quanto a capacidade de Pessoas om transtorno mental, é reforçar essa proposta da Reforma Psiquiátrica, incluindo os mesmos na sociedade, com inclusão produtiva.

Em um momento de competitividade no mercado de trabalho, as pessoas com transtorno mental, estão em desvantagem, pelas limitações que apresentam ao transtorno, logo a inserção em mercado de trabalho, fica muito difícil.

Gugel $^{3}$ reforça a questão desta inclusão em cooperativas sociais, pois no momento em que se edifica a Lei das Cooperativas Sociais destinadas às pessoas com deficiência em desvantagem econômica, a sociedade avança para a legitimidade deste compromisso fundamentado em leis, outra garantia constitucional que é a liberdade de funcionamento de cooperativas ( $5^{\circ}$, XVIII, Constituição da República), sob o qual se sustenta todo o sistema nacional.

Nessa busca de fortalecer a autonomia e inclusão social dos pacientes, em oficina terapêutica, nominada de Oficina Produtiva, foram emprestados pela Secretaria do Trabalho e emprego, três máquinas de costura, e com roupas descartadas, iniciou-se a confecção de estopa. Era complicada a utilização das roupas, pelo tipo do tecido e a higiene que as roupas chegavam, mas foi dessa maneira que os pacientes aprenderam a montagem, e manejo nas máquinas.

Com essa oficina ressurgiu a ideia de montar a cooperativa um desejo dos pacientes de muito tempo, e inicialmente foi realizado um planejamento, e os mesmos em conjunto com a equipe técnica do CAPS II. A equipe comprava nossa produção, compartilhava nossas demandas, buscavam doadores, todos compraram nosso sonho. Tínhamos total apoio da coordenação para a condução do trabalho.

Nessa perspectiva a busca da implantação da cooperativa esse trabalho do CAPS II, na construção de uma rede comunitária de cuidados, que se torna fundamental para a consolidação da Reforma Psiquiátrica, buscando emancipação das pessoas com transtornos mentais. Em concordância com as legislações trabalhar no território significa assim resgatar todos os saberes e potencialidades dos 
recursos da comunidade, construindo coletivamente as soluções, a multiplicidade de trocas entre as pessoas e os cuidados em saúde mental.

É possível a mudança na sociedade, mas devemos pensar como superá-las, mas para isso precisa se trabalhar com participação de todos os envolvidos. Buscando entender a história e não entrar na falácia que é assim mesmo, sempre foi assim, e não vai mudar. Interpretamos que a experiência vivenciada do trabalho no CAPS, se traduz nessa reflexão de Paulo Freire:

Quanto mais crítico um grupo humano, tanto mais democrático e permeável, em regra. Tanto mais democrático, quanto mais ligado ás condições de sua circunstância. Tanto menos experiências democráticas que exigem dele o conhecimento crítico de sua realidade, pela participação nela, pela sua intimidade com ela, quanto mais superposto a essa realidade e inclinado a formas ingênuas de encara-la. A formas ingênuas de percebê-la. A formas verbosas de representa-la. Quanto menos criticidade em nós, tanto mais ingenuamente tratamos os problemas e discutimos superficialmente os assuntos. (Freire, Paulo. 1977, pg. 95)

A visão que concebida desse trabalho é que estamos apreendendo na Saúde Mental, no CAPS, local de democracia onde o usuário se manifesta na sua vontade, da maneira que deseja se expressar, sem termos que traduzir a sua vontade, ou colocarmos para ele a "sua vontade".

É um aprendizado rico, e desafiador, muitos de nós profissionais temos um discurso teórico de que devemos emancipar os usuários que atendemos, mas na maioria das vezes estamos com a nossa cultura arraigada de detentores do saber, de técnicos com a receita do bolo, e desacreditando na capacidade dos que tem um jeito diferente de ver o mundo.

Se faz necessário criar novos espaços apreender a fazer diferente, com a certeza que não somos os detentores de conhecimento, mas que vamos apreender e ensinar com os usuários. Na prática profissional devemos estar disponíveis ao movimento, a tentar novas experiências e que sim podemos estar equivocados muitas vezes. Olhar o sujeito que deve ser livre, e nesse caminho chegar com eles.

\section{A CONSTRUÇÃO DO SONHO ARAUSOL}

".... Ninguém caminha sem aprender a caminhar, sem aprender a fazer o caminho caminhando, sem aprender a refazer, a retocar o sonho por causa do qual a gente se pôs a caminhar. "Paulo Freire ${ }^{2}$

Neste movimento o desenvolvimento da cooperativa era uma busca na conquista autonomia para os pacientes e quebrar paradigmas na sociedade, quanto a capacidade de Pessoas com transtorno mental, reforçaria a proposta da Reforma Psiquiátrica, incluindo os mesmos na sociedade, com inclusão produtiva.

Através da oficina produtiva, sempre ouvindo os usuários, suas demandas, seus desejos. Foi uma inciativa de construção coletiva, onde foi iniciado com confecção de estopa com reaproveitamos de roupas usadas. Era complicada a utilização das roupas, pelo tipo do tecido muitas vezes não apropriado para a estopa e a precária higiene que as roupas chegavam, mas foi dessa maneira que os pacientes aprenderam a montagem, e manejo nas máquinas. Já pensando na questão de sustentabilidade

\footnotetext{
${ }^{2}$ Freire, 1992 apud Freire 2001, p. 199.
} 
e reaproveitamento, com produção de estopa, utilizando rejeitos de tecidos, de empresas de confecção, descartados.

O conceito de sustentabilidade em um primeiro momento leva-se a reflexão sobre ações ambientais que minimizem os níveis de degradação e possibilitem garantir o atendimento das necessidades presentes sem com isso comprometer $\mathrm{o}$ atendimento às necessidades das gerações futuras, conceito que é mais amplamente conhecido como desenvolvimento sustentável. Apostando nesta buscou-se empresas para auxiliar seu descarte de tecidos, e que era a matéria prima.

Os usuários se dispuseram a buscar com ofício da Associação as empresas têxteis em Curitiba, solicitando retalhos de descartes, para a confecção de estopa. Os pacientes se identificaram, e colocaram a perspectiva da implantação da cooperativa, e sua relevância nas suas vidas, seus familiares e do meio ambiente. Nessas visitas, foram doados muito materiais, inclusive, tecidos novos, e com um cronograma de recolhimento de retalhos, quinzenalmente.

Impressionante como o movimento dos pacientes em buscar os retalhos, aumentou a autoestima e confiança, que seria possível a implantação da cooperativa. Os pacientes retornaram ao serviço e em reunião da Associação, repassaram suas conquistas e seus planos, para futuro.

Ao buscar as empresas Têxteis fomos acolhidos, e com uma demanda de tecidos que os fornecedores tinham dificuldade em descartar. Relatavam que poderíamos manter um cronograma quinzenal para recolher o material, sem custos, e após contato com algumas empresas fomos procurados por outras, solicitando que buscássemos os rejeitos.

Inicialmente como não se tinha conhecimento do mercado da estopa e nem acesso a empresas, utilizava-se roupas doadas como já referido, mas após a utilização dos retalhos a condição de trabalho melhorou e foi mais ágil, e adequada.

A confecção das estopas e a montagem, foi um aprendizado muito rápido, e cada paciente tem seu ritmo, mas com condições de produção e com um viés terapêutico, perceptível. Os pacientes em reuniões da associação fortalecem a importância que eles e a cooperativa tem na proteção do meio ambiente.

Após algum tempo de produção com retalhos fomos nas empresas e ganhamos uma grande quantidade de tecido Jeans, que além do seu valor comercial, eram peças inteiras de tecido, e em conjunto decidimos que deveríamos decidir qual produto produzir, aproveitando esse material de forma adequada e não era adequado para a confecção da estopa.

Decidimos então em fazer camas para Pet, procuramos na internet modelos, e com apoio da equipe e de simpatizantes fomos financiados a comprar os insumos necessários que faltavam para tal produção. Como por exemplo fibra de silicone, laços, linhas, etc.

Em pouco tempo para nossa surpresa nossa produção estava com qualidade para comercialização e a produção foi sendo realizada de forma mais rápida. Nesse processo de trabalho não tínhamos como escoar a produção e não sabíamos como legalizar a questão de transformar a Oficina Produtiva em Cooperativa. 
Nosso grupo se reunia duas tardes por semana, no CAPS II, em uma sala reservada para nossa Oficina, e estávamos muito contentes com os resultados produtivos. A união do grupo, a melhora na saúde dos usuários, o aprendizado da produção, entender como funcionava o processo de produção era enriquecedor.

Entendemos como o trabalho pode ser emancipador, como a produção pode trazer realização ao ser humano, trazer felicidade, e principalmente a confiança em si mesmo. Para pessoas que eram acostumados a serem desacreditados, que não tinham possibilidade de inserção em mercado de trabalho, realizar sua própria produção, participar do processo de construção de trabalho, foi uma vitória.

Neste movimento citado anteriormente, buscávamos escoar a produção e regularizar a situação da Oficina Produtiva, e decidimos fazer um curso na Universidade Federal do Paraná. Em 25 de abril de 2019, o Curso Economia Solidária, Geração de Trabalho e Renda e Possibilidades de Práticas na Saúde Mental. Esse curso foi proporcionado pela Associação Libersol, que apoia a Saúde Mental e empreendimentos como o nosso. Através do Professor Luís Ferro, e sua equipe, da Universidade Federal do Paraná, fomos apreendendo, sobre as feiras onde escoaríamos nossa produção e como trabalhar com a Economia solidária.

A Libersol nos fortaleceu, abriu nossos horizontes e auxiliou para instrumentalizamos nosso trabalho. Neste curso percebemos a dificuldade do nosso país em implantar cooperativas, decidimos então solicitar auxílio da Associação Regis Viola, para concretizar nossos objetivos.

A questão de implantação da cooperativa tem como entrave a situação previdenciária dos usuários, pois caso sejam cooperados não tem acesso a nenhum benefício ou auxilio, pois configuraria para o INSS que podem ser inseridos no mercado de trabalho.

Após estudo em conjunto com equipe da Libersol, sobre como regularizar nossa situação, desenvolvemos a Arausol, como um projeto de Geração de Renda e Economia Solidária dentro da Associação Regis Viola, e os participantes eram remunerados como bolsistas. Foi a Associação Regis Viola que nos deu suporte referente a essa questão legal.

Neste contexto, a Economia Solidária, é uma busca de lutar contra a exclusão social e econômica. Buscando fomentar a discussão e da exclusão das pessoas com transtornos mentais do mercado de trabalho. Os movimentos da Reforma Psiquiátrica e da Economia Solidária tem princípios fundamentais no que se refere a opção ética, política e ideológica por uma nova ordem societária, marcada pela solidariedade.

Apreendemos muito com este processo de trabalho, como enfrentar as dificuldades com garra, com esperança e com muita fé no outro. Juntos trilhamos conquistas, que para a maioria da sociedade pode ser ínfima, mas para nós que lutamos diariamente com a exclusão e preconceito, é uma vitória imensa.

Atualmente o Projeto Arausol, tem onde escoar produção, comprou maquinas de costura, os insumos, participou de projetos com empresas parceiras e também teve publicizado sua trajetória no jornal local. 


\section{CONSIDERAÇÕES FINAIS}

Através desse relato pode-se compreender como é possível existir nova forma de produção, sim necessitamos de maior investimento do poder público, de leis mais fortalecidas, mas precisamos acreditar que é viável economicamente. Também que nos conscientizar de que a sociedade pode auxiliar comprando desses empreendimentos solidários, que respeitam a forma de produção, que cuidam do meio ambiente, e principalmente incluindo pessoas que estão à margem da sociedade capitalista.

Sabemos que para a manutenção financeira dos usuários ainda temos uma caminhada, somos uma criança ainda com menos de três anos, dando os primeiros passos. Foi necessário a mudança de planos de cooperativa para Projeto de Geração de Renda.

As conquistas aqui apresentadas já demonstram que é possível a produção de qualidade, saímos do caráter de oficina do CAPS II, para um empreendimento, mas principalmente a melhora na qualidade de vida dos usuários, a melhora na sua condição de saúde mental, na questão cognitiva, afetiva e de aprendizado de situações cotidianas, é visível e impressionante.

Esse trabalho com princípios e valores como a democracia, o interesse pela comunidade, a educação, a responsabilidade individual, a responsabilidade social, a equidade, a igualdade, a ajuda mútua e a solidariedade

No caso dos pacientes do CAPS II de Araucária, buscava-se a inserção e no mercado, onde muitas vezes produtores isolados, e de pequeno porte tem dificuldade de inserção no mercado.

Surpreendente foi como pacientes comprometidos conseguiram produzir, cada um com seu ritmo, mas aprender a montagem e manutenção, e como eles estavam empoderados para tomada de decisões e busca de fornecedores, planejamento sobre novos aproveitamentos de rejeitos. Também foi nítida questão da auto-estima dos pacientes, como cidadãos produtivos e protetores do meio ambiente, sujeitos de direitos.

A proposta de estudo para identificar essa viabilidade da autonomia dos pacientes, foi comprovada com o decorrer da pesquisa, com o fortalecimento da autonomia, a construção de sujeitos de direitos e a inserção produtiva.

O trabalho neste grupo encanta, pessoas superando limites e angariando conquistas, sendo fortalecidas em seu movimento de emancipação. Acreditamos que é possível e vivenciamos isso, na prática.

Cada vida que se ilumina, ilumina a todos ao seu redor, isso foi perceptivel, e isso nos emocionou. Este projeto iluminou os trabalhadores e o serviço, trazendo na prática a realidade da transformação que sonhávamos, e todos nos sentimos parte deste processo, logo fomos transformados nele.

\section{REFERÊNCIAS}

BRASIL. MINISTÉRIO DA SAÚDE. SECRETARIA DE ATENÇÃO À SAÚDE DEPARTAMENTO DE AÇÕES PROGRAMÁTICAS ESTRATÉGICAS. Saúde Mental no SUS: Os Centros de Atenção Psicossocial. Brasília: Ministério da Saúde, 2004. 86 p.: 1. Saúde mental. 2. Acesso aos serviços de 
saúde. 3. Prestação de cuidados de saúde. I. Brasil. Ministério da Saúde. Secretaria de Atenção à Saúde. Departamento de Ações Programáticas Estratégicas. II. Título. III. Série.

BRASIL. Ministério da Saúde. Secretaria de Atenção à Saúde. DAPE. Coordenação Geral de Saúde Mental. Reforma psiquiátrica e política de saúde mental no Brasil. Documento apresentado à Conferência Regional de Reforma dos Serviços de Saúde Mental: 15 anos depois de Caracas. OPAS. Brasília, novembro de 2005.

BRASIL. Constituição Federal. Brasília.

BRASIL. Lei ${ }^{\circ}$ 12.305. Institui a Política Nacional de Resíduos Sólidos. Disponível em: Acesso em: 17 abr. 2015.

BERNARDO, José. Sustentabilidade Ambiental e Sustentabilidade Social: Os Limites e Avanços do Programa Coleta Seletiva de Lixo no Município de Cabo de Santo Agostinho, 1998/2004.

COELHO, Christianne Coelho de Souza Reinosch. A questão Ambiental dentro das industrias de Santa Catarina: uma abordagem para o segmento industrial têxtil. 1996

FARIA, Carmen Rachel Scavazzini Marcondes. A política Nacional de resíduos sólidos. Senado Federal, Núcleo de Estudos e Pesquisas. Boletim Informativo nº 12, de 2012.

FREIRE, Paulo. Educação como prática de liberdade. $7^{\circ}$ ed.Rio de Janeiro, Paz e Terra, 1977. 150 p.

GUGEL. Maria Aparecida, Cooperativas Sociais e as Pessoas com Deficiência. http://www.ampid.org.br/ampid/Artigos/Artigo MGugel 2.php, consulta dia 11/02/2019 ás 17h50m.

GIL, Antonio Carlos. Métodos e Técnicas de Pesquisa Social. 5º ed. Atlas: São Paulo, 1999.

MAUAD, Marcelo José Ladeira. Cooperativas de Trabalho - sua relação com o Direito doTrabalho - São Paulo : Editora LTR,1999.

MINAYO, Maria C. De Souza. Org. Pesquisa Social: Teoria, Método e Criatividade. Vozes, Rio de Janeiro, 1994.

PEREIRA, Maria Concebida. LOUZADA, Roberto. VALORAÇÃO ECONÔMICA DOS RESÍDUOS SÓLIDOS TÊXTEIS. https://www.franca.unesp.br/Home/Pos-graduacao/planejamentoeanalisedepoliticaspublicas/iisippedes2016/valoracao-economica-dos-residuos-solidostexteis.pdf , consulta dia 09/03/2019, as 9h00m .

PORTARIA No 336, DE 19 DE FEVEREIRO DE 2002: O Ministro da Saúde, no uso de suas atribuições legais; considerando a Lei 10.216, de 06/04/01, que dispõe sobre a proteção e os direitos das pessoas portadoras de transtornos mentais e redireciona o modelo assistencial em saúde mental;

RESOLUÇÕES. Conselho Nacional do Cooperativismo. www.ocb.org.br .

SINDITEXTIL-SP. Retalho Fashion. Em notícia. Julho 2012. Ano VII. № 25. Disponível em: Acesso em: 25 mar. 2016.

http://dab.saude.gov.br/portaldab/smp_ras.php?conteudo=rede_psicossocial consultado dia 18/03/19 ás 19h20m São diretrizes da Rede de Atenção Psicossocial: 